\title{
CONGRATULATIONS TO \\ VLADIMIR EMEL'YANOVICH SOKOLOVICH
}

Doctor of Technical Sciences

\section{ON YOUR 95th BIRTHDAY}

Vladimir Emel'yanovich Sokolovich is an outstanding scientist in the fields of chemical soil stabilization and analytical chemistry.

Mr. Sokolovich has developed more than 20 methods for the stabilization of soils, including the single-grout method of silicatization using silicon fluosilicate formulas, the single-grout method based on inorganic and organic polymers for the stabilization of carbonate soils and strengthening of filtering concretes, the single-grout method for the nontoxic resinification of soils, the stabilization of fissured and karst-prone rocks by foamed cement grouts, the ecologically pure drill-and-blend method of stabilizing marine slimes, and the method of electrochemical anchoring in clayey soils. Mr. Sokolovich's studies involving the development of sulfate-resistant grouting mortars have been highly rated in hydrotechnical construction.

Mr. Sokolovich is a multifaceted scientist He has accomplished much in the fields of soil science, engineering geology, and ecology, and developed original methods for elimination of the large amounts of dioxines contained in slime accumulators at numerous chemical plants in Russia. He has also developed his own version for the prediction of earthquakes and aviation catastrophes.

He has authored more than 300 published works including three monographs, 82 author certificates, and hundreds of qualified reports. He has prepared 18 Candidates, and three Doctors of Technical Sciences.

Mr. Sokolovich's scientific school of chemical soil stabilization has received widespread recognition, and has become one of the basic schools in Russia and abroad.

In addition to being a talented scientist, Mr. Sokolovich possesses excellent human qualities exceptional industriousness, deep-seated educational development, broad erudition, kindliness, and amiability.

The editorial office, editorial staff and the RSSMGFE extend hearty congratulations to you, dear Vladimir Emel'yanovich on your jubilee, and wish you health and happiness. 